\title{
Geographic Information Systems In NePal And Its Way Forward
}

\author{
Krishna Prasad Poudel, PhD \\ Professor, Department of Geography Education, T.U., Nepal \\ kpoudel_pokhara@yahoo.co.uk
}

\begin{abstract}
GIS is now becoming a demanded crosscutting subject at the universities and many other institutions. It has introduced academic courses at different levels. Similarly, a number of commercial entrepreneurs are investing good amount of resources as well as several development agencies focusing on GIS-based decision support systems. Nepalese organizations including all governmental, non-governmental and social as well as at individual level are also investing quiet a good amount of resources on it. In this context the development of GIS in Nepal and its social responsibility has to be analyzed critically. In this paper focus has been given to search the space of GIS in the Nepalese governmental, non-governmental and academic institutions and so on. The study has been found many institutional setups have the provision to work with due consideration to the spatial dimensions. Many of them have already procured hardware, software and also investing quite a good amount of money. In practice, several such organizations have very less output. In this context, while going through the analysis, some challenges appeared are highlighted and a way forward has been given to its development.
\end{abstract}

Key Words: Geographic Information Systems, GIS-based decision support systems, GIScience, Spatial Data Infrastructure, National GeoDatabase Center

\section{INTRODUCTION}

Geographic Information System (GIS) is a new field of academic discipline developed since 1960s as computer applications for handling volumes of information obtained from maps as well as for performing operations that would otherwise be too tedious, expensive, or inaccurate to perform by hand (Aronoff 1989; Peuquet and Marble 1990:50). It has an upward trend in philosophical understanding, scientific research, development and applications. Both in technologically highly developed world and in the least developed parts of the world, GIS is now coming up with different forms, processes and structures. In its development process, the domain of GIS has been shifted from tools in early days, then systems and in the recent years it is transforming to sciences. Recent trends have been toward the development of GIScience and Technology (Goodchild 2004:710). Therefore, it is named as 'GIScience', which has been comprising a strong drive towards integrating scientific methodology and reasoning into community-centered initiatives particularly to deal with spatial informationgathering and decision-making. Researchers around the world have been working on different approaches known under a variety of abbreviations including, among others, Public Participation Geographic Information Systems ((PPGIS), Participatory GIS (PGIS), Community Integration GIS (CiGIS) and Mobile Interactive GIS (MiGIS)
(Rambaldi, and Callosa-Tarr, 2002:1), entrepreneur GIS and web GIS. It also has been integrated with many other disciplines and named accordingly for example, integrating GIS with Management Information System and named it GMIS.

Similarly, Geographic Informated System (GIS) has been developed in an integrating form of knowledge and the application of space technology. Earth Observation (EO) technology was the first of its kind to detect surface resources heavily developed after 1970s. It also came into the commercial realm in a considerable way thereby expanding access to these technologies to the public. In the recent years, this technology has been enjoying great potentiality because of more and more practical applications involved. The merging of spatial technologies with the flexibility and resourcefulness of internet and wireless communications devices is opening up of new vistas of significant applications and having great impact on the way of information is generated, analyzed and presented. Thereby it is becoming easier in special considerations in policy and decision making processes.

At the grass-root society level, the system places people in the position to generate and analyze geo-referenced spatial data and integrates multiple realities and diverse forms of information. This would in turn enable broader public participation in environmental and public policy decisionmaking. Nonetheless, it has become apparent that, 
due to its heavy technological component, the community use of GIScience cannot be separated from the resource issues necessary to undertake and maintain it. Therefore the external support in terms of technological capacity building is inevitable; otherwise GIScience would be outside the capacity of most marginalized or less-favored communities (Weiner et al. 2001; Dunn et al., 1997 cited in Rambaldi and Callosa-Tarr, 2002:1).

\section{METHODS AND MATERIALS}

This paper is poepared based on review of secondary sources, available in published documents, books and internet.

\section{GIS IN NEPAL}

The National Remote Sensing Center was the pioneer organization to establish the history of digital spatial database of Nepal which was established with the financial and technical support of USAID in 1979. Government of Nepal has released its forest coverage map of Nepal based on Multi Spectral Scanner (MSS) data of American Remote Sensing Satellite i.e. LANDSAT in early 1980s. At the National Remote Sensing Center, more focus had been given to the satellite based forest coverage mapping with image processing and raster database analysis with the help of ERDAS software. The concept of vector database handling GIS system has been started after the establishment of Mountain Environmental and Natural Resources Information System (MENRIS) in ICIMOD in late 1980s.

The application of spatial technologies has gradually expanded to cover other areas of environmental management. More remarkable development in this regard has been initiated by United Nations Environment Programme (UNEP) during first half of 1990s when systematic efforts were launched to create digital database with diverse thematic orientations. Since then number of government organizations and universities have acquired spatial technology. Many students and professionals have been receiving their degree in GISciences. Besides these efforts a number of students graduating from foreign universities are also in rise. Enterprises based on offering Spatial Decision Support Services (SDSS) are also being increasing. A number of government departments have been included provision for creating digital database in their annual programme.

After the Ninth Five Year Plan (1995-2002) the Government of Nepal has been incorporating the use of GIS and RS technology for the preparation of land use map of the country as a key planning aid.
It has also stipulated the need to prepare resources inventory of the country in digital form. Similarly, the Local Self Governance Act (LSGA) 1999 has also made mandatory for preparing the local level resources inventory in the forms of digital database of areas under jurisdiction of each local government outfit.

The Tenth Five Year Plan (2002-2007) has accorded high priority on poverty alleviation strategy and also highlighted the importance of poverty mapping of spatial units of local governments like Village Development Committees (VDCs), Municipalities, and District Development Committees (DDCs) as a key element of strategies aimed at poverty reduction. The need to factor in spatial dimensions and leverage available technological means, for example GIS and RS technologies to achieve this end has been amply articulated in government directives and policy pronouncements. The Three Year Interim Plan (2008-2010) has also been proposed to prepare the GIS database of the country. The first Democratic Republic Government has also envisaged the spatial database based planning in its Minimum Common Agendas for operating multiparty joint government. Beyond the barrier of local level planning, several current issues like monitoring climate change, disaster reduction, forest resource survey, land use and land cover mapping, infrastructure mapping and hydropower plant construction are some of the potential sectors where the spatial technologies are commonly applied. Vertical integration of location specific data capture and acquisition through the space technologies and analysis by maintaining specific accuracy level in GIS provides high potentiality of data linkages as well as merging of voluminous information in a single platform.

The GIS laboratory within the country was established in the National Planning Commission Secretariat with a view to strengthening the decentralized planning activities with the support of UNDP in 1992. The capability of the laboratory and its resourcefulness in terms of being able to contribute to up-stream policy supporter has remained more or less static. Furthermore, one of the UNDP supported programmes has established a GIS Center at the Ministry of Local Development as well to support the Local Governance related activities. Those laboratories still have faced problems of human resources and depending on consultants supported by the donor agencies.

Over sixty organizations including government, private and academic institutions were recorded for some kind of GIS activities with their computer laboratory in 2011 (NEGISS, 2011). Some of the key government agencies like Ministry of Federal Affairs and Local Development, Department of Survey, 
Department of Irrigation, Department of Mines and Geology, Department of Roads, Department of Urban Housing and Building Construction, Department of Water Supply and Sanitation, Nepal Telecom, Nepal Electricity Authority, Ministry of Defense, Ministry of Agriculture Development and National Agriculture Research Center and Central Bureau of Statistics have established some form of GIS and RS laboratory and information systems - a process that started prior to 1995. With some exceptions these laboratories are in function, however, their work has yet to transcend departmental boundaries to be able to serve larger goals. On the front of human resources development and training the universities in the country (i.e Tribhuvan, Kathmandu, Pokhara and Purvanchal) have introduced GIS and RS curricula during the early days of 1990s as complementary courses of respective degree programme. But no universities inside the country have developed the specialized courses so far. Recently, UNIGIS International Centre has been opened for the MSc GIScience and Systems in Kathmandu with a goal to build international level human resource capacity with the affiliation of Salzburg University, Austria (http://www.unigis.net/kathmandu). These long lists show GIS getting its popularity in the country and now a good efforts have been made towards its application. However, there are some challenges associated with its development.

\section{CHALLENGES}

GIS has been used in various organizations for different purposes for a long time. However, it has certain challenges in its development.

\section{i}

\section{GIS Center}

GIS technology has been adapted by various organizations, institutions and universities within the country and investment of capital, time and efforts in a huge scale has been made for hardware, software and database. However, it lacks coordination, networking and standardization of the activities. GIS-based database are found in parts and patches. There is no central database depository from where users could get information easily. Even for decision makers, it is hard to find out data. Therefore, large amount of money and time used to invest on data collection. There is lacking of National Spatial Data Center (NSDC), no National Spatial Data Infrastructure (NSDI), and no standardization about the ontology of geographical objects by which nation has hard time to transform from the analog to digital information technology.

\section{ii Capacity building}

In the Nepalese context, major challenges of the GIScience discipline are concerned with the cartographically accurate mapping of 'verticality' and 'variations' of the rugged earth surface. A numbers of algorithms of mapping are basically developed in the context of homogeneous terrain and highly developed technical and civil society and much of the borrowed knowledge has limitations in Nepal's ground reality. Uniformity, accuracy, applicability and sustainability are major components of the curricula in the real context. To this point, the GIScience curricula has to fulfill the challenges of:

- Appropriate methodologies, techniques, and algorithm for mapping the physical, social, cultural and economic diversity of the country

- Integration of the knowledge and wisdom

- Building vertical linkages from a least investment on education sectors to the hightech scientific achievements

- Job market, placement and opportunity of personality development and income from the investment on education sector

Focusing on these realities, academic curricula have to be concentrated on the fulfillment of the issues pertaining at local to global arena, more specifically in the spectrum of GIScience. GIScience graduates have to be enabled to address local issues like:

- Geometrically and cartographically accurate mapping of the individual, public and common properties, resources and spatial information for scientific concerns

- Dissemination of the information to the concerns, an individual and the policy level

However, in the global level GIScience graduates have to be enabled to link local and national specific contextual problems with world standard scientific achievements in the field of GIScience and Technology.

\section{iii Database management}

The fundamental part of GIS is its database, which has key roles on its layer extraction, uniformity among the sources, resolutions, transformation, accuracy and classification types and algorithms of the variables. In the Nepalese context, these are becoming issues and often talked widely but there is hard time to get in consensus. Different organizations have their own mandate and logic to carry out the activities. The major lacking part is no national level guidelines for the spatial data and guiding principles.

\section{iv Data security}

GIS always works for digital datasets and its security parts concerned with its physical security 
and piracy. Capability of hardware and their sustainability within the stipulated time duration, software capability and compatibility with newly emerging and inventions and its long-term security provisions in terms of storage conditions are always concerned with the physical security parts of the database. In the meantime security of warehouse from other physical damage like fire, earthquake, dump and fungus are major causes of its life threats.

\section{v. Data sharing}

It is a common estimation that over 70 percent budget of any GIScience related project goes to the database collection. This shows data collection has the heavy weightage (investment) of any GI related project. Both time and money required for database collection can be saved by doing an effective data sharing policy among the institutions / organizations. For this a clear policy on sharing, value added costing and access to other users has to be made by the nation.

\section{vi Data marketing}

Education in Nepal is still cheaper than many other countries of the world. And also the country has cheaper cost of leaving compared to other parts. Nepal can establish standard academic institutions for the better quality human resource production in the field of GIScience, too. With these investments, Nepalese professional can work out sourcing in the field of GIScience. Providing better jobs to GIScience professionals, Nepal government has to work with clear financial policy on its digital transaction of the spatial data. A clear financial policy is directly related with transaction of digital data through the wire transformation because of its lacking, present outsourcing market is facing serious problem.

\section{vii Right-to-Information (RTI) and Digital Privacy}

In a democratic process, information is the power. Public awareness programme is backed by information. But there is trade-off on cost recovery systems and its security persuasion. Spatial data have clear positional accuracy and also referenced with several other attributes which may have the attachment of personal information of even an individual, institution and any geographical territory. In such condition, misuse of data might be a great threat for any individual or to the nation.

\section{THE WAY FORWARD}

Data availability, accuracy, reliability and easy access are the major concerns for planners, policy designers, field workers, researchers and learners. In many cases, the available data are also found with inconsistencies on time, naming convention, and facts and figures. Specifically in spatial data, inconsistencies problems are found in projection and transformation, scale and resolution and more often are lacking error level, meta data, acquisition source and base-map information. Several such data are usually found unofficially copied and violation of minimum professional ethics. Networking and data sharing are hardly in practices in official and authorised level. Therefore, in combating these practices National Geo Database Center (NGDBC) has to be established. That Center could work as database warehouse where data standardization, quality control and monitoring, networking and data sharing among the stakeholders operate. This will develop a ground for policy framework for spatial auditing of development work where development activities critically verified with ground based spatial information instead of existing practice of expenditure invoice.

NGDBC has been proposed for one window policy to data acquisition, storage, management, quality monitoring, security maintaining and dissemination. Such Center can be established at the national organization like National Planning Commission (NPC) or any other high level autonomous organization which can be worked at central level. At the beginning the working modality of the NGDBC can be initiated by some working responsibilities such as, data tracking and compilation, quality maintaining and monitoring, maintaining historical records, data security assurance and dissemination to public and other users (Fig. 1).

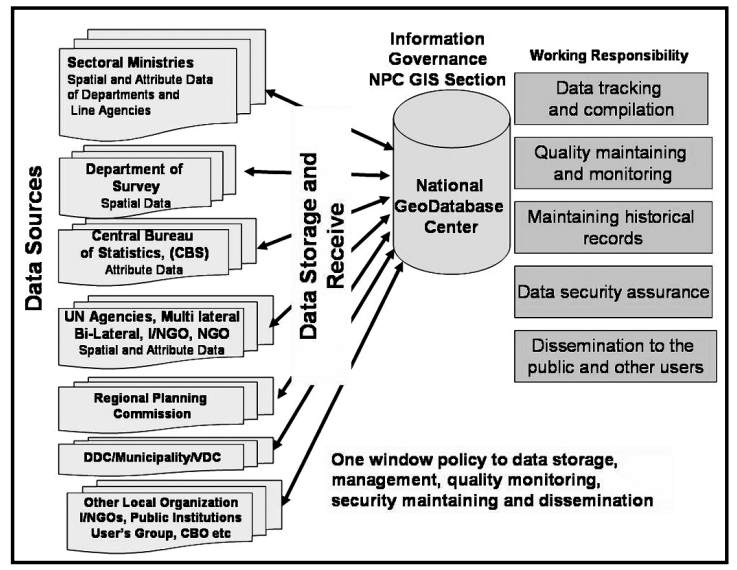

Source: Adapted from Poudel, 2010

Figure 1: A Structure of National GeoDatabase Center (NGDBC)

The national data have to be collected from different Ministries and their line agencies, UN agencies, multilateral and bi-lateral organizations, I/NGOs, NGOs, Regional Development Organizations, District Development Committees, Municipalities, Village Development Committees, other local organizations, 
public institutions, User's Group and community based organizations. More specifically, the spatial data of the Department of Survey and attribute data of the Central Bureau of Statistics have to be compiled and link in GIS environment for its wider application. The NGDBC has to act as a central hub of the database. It has to be framed according to the principle of Public Private Partnership (PPP) modality. This governing body would work on policy formulation, strategy designing and networking at the higher level. Here the large responsibility is envisaged for the designing of national planning strategies based on the geospatial database structures which could have a strong capability to replicate spatial variation, development amenities differentiation, and social exclusion and development gaps. Social, cultural, spatial and economic inclusion can only be incorporated by integrating all sorts of information in a single holistic approach. After all, it could achieve the rationality of planned development.

The proposed model of NGDBC simply looks like a center managed database model. However, it requires thinking in more liberal way and needs to compile, store, manage and disseminate information as an enterprise level rather than to single body control modality. Basically, the questions are used to put on the cost of the data collection, price determination, ownership issues and benefit of the entire exercise. The major management issues are 'who suffer, who gain, and what I or we get' ultimately after doing this work. Undertaking these very questions rational procedure of governance mechanism is required to follow. More specifically, NGDBC has to be managed within the framework of enterprise database management system by putting all concerns in a win-win situation. Base price of each data set has to determine for all types of stakeholders i.e. government, private, and individual as well as for profit making and volunteer's work. Similarly, the rules of patent right, copy right and user's right all have to set in accordance with the jurisdiction of 'Rights to Information' mandate. Base price and value added price of each data set has to be quoted and it needs to follow the transparent democratic norms on data dissemination and use of information. One window database management system will help to follow all these mechanism which ultimately control data piracy, duplication, redundancy and gap. Now it is high time to think the data management modality in a proposed federal structure of the country. Existing uni-model of data collection and management system may not exist in the federal system. Therefore, it is essential to design database management system suitable and sustainable in changing context.

\section{CONCLUSION}

The geographical diversities including its spatial variations and socio-cultural milieu of the nation have been imparting several differences in the country. Many diversified facts directly articulate in the development activities. Practices on formulating policies to implementing and finally monitoring and evaluation strongly require myriad of information associated with space, action, processes, result and impacts within or beyond the territorial boundary. Unless putting all the information in a single whole adopting by its basic norms of integration and synthesizing each and every facet, it is difficult to draw consequences of the action in a holistic approach which is indispensable for the nation building in a sustainable course. Taking these views in mind, GIScience requires working toward development of the academic curricula by adopting the hierarchical and vertical linkages of the knowledge and also integrating it with broad spectrum of wisdom of the society. It, further, requires adopting the methods, algorithm, techniques specific to the local geographical contexts and reality. However, as it is proposed for NGDBC central hub, it needs to strengthen capacity of human resources and adding physical infrastructure, building coordination with different sectoral ministries and their line agencies as well as private and corporate vendors, individual experts and adopt spatially thinking culture for development activities at local, regional and national level.

\section{REFERENCES}

Aronoff, S. 1989. Geographic Information System: A Management Perspective. Ottawa: WDL Publishers

Dunn, C. E.; Atkins, J. P. and Townsend G. J. 1997. GIS for development: a contradiction in terms? Area. Vol. 29, No. 2, 151-159.

Goodchild, M. F. 2004. GIScience, geography, form, and process. Annals of the Association of American Geographers, 94(4):709-714

NEGISS, 2011. Geographic Information System Users Survey in Nepal report submitted to the High Level Commission for Information Technology (HLCIT) Government of Nepal, Nepal GIS Society, Jawalkhel, Lalitpur

Peuquet, D. J. and Marble, D. F. 1990. What is a Geographic Information System? In Donna J. Peuquet and Marble F. Duane (eds) Introductory Reading in GIS. New York: Taylor and Francis

Poudel, K.P. 2010 Building national geodatabase center. GIS Newsletter (Trimesterly Newsletter of National Planning Commission Secretariat, Singha Durbar), Kathmandu, Nepal. Issue 24-25 (June): 2-6.

Rambaldi, G. And Callosa-Tarr, J., 2002. Participatory 3-Dimensional Modelling: Guiding Principles and Applications. ASEAN Regional Centre for Biodiversity Conservation (ARCBC), Los Baños, Philippines

Weiner, D., Harris, T. and Craig, J.W. 2001. Community Participation and Geographic Systems. Paper presented at the "ESFNSF Workshop on Access to Geographic Information and Participatory Approaches Using Geographic Information. Spoleto, 6-8 December 2001. 